\title{
COMUNICAÇÃO EMPRESARIAL: FONTE DE ESTÍMULO À PRODUTIVIDADE
}

\author{
https://dx.doi.org/10.48097/2674-8673.2021n4p04
}

\author{
João Paulo Oliveira Chaves ${ }^{1}$ \\ Thales Cavalcanti Araújo ${ }^{2}$ \\ Arandi Maciel Campelo ${ }^{3}$
}

\section{RESUMO}

O tema deste artigo aborda a comunicação, conflitos na organização, clima organizacional e produtividade na empresa KarneKeijo Logística Integrada. O estudo teve como objetivo identificar os métodos de comunicação entre os colaboradores, analisando a forma como a comunicação entre setores contribui para a produtividade empresarial, além de observar a causa de conflitos na empresa, sugerindo uma forma de conciliação, visando o bem comum a todos. O levantamento e a análise foram feitos por meio da pesquisa de campo através de um questionário semiaberto aplicado entre 21/10/2019 a 24/10/2019. Das 76 pessoas envolvidas entre o setor comercial e de transporte da empresa, 19 (25\%) participaram do questionário. $\mathrm{O}$ estudo revelou que a comunicação é fundamental para uma empresa ser produtiva, pois ela abrange todas as etapas do processo e do relacionamento entre pessoas, criando também um ambiente favorável a se trabalhar quando feita de maneira correta. Também foi observado que existem sempre conflitos na empresa, porém não são tão relevantes na maioria dos casos e a forma de resolvê-los é muito rápida e eficaz.

Palavras-chave: Comunicação. Cultura organizacional. Motivação. Conflitos. Influência pessoal. Qualidade profissional.

Data de submissão: 07/10/2020

Data de aprovação: 04/11/2020

\begin{abstract}
The theme of this article addresses communication, conflicts in the organization, organizational climate and productivity in the company KarneKeijo Logística Integrada. The study aimed to identify methods of communication between employees, analyzing how

1 Estudante do curso de Administração da FMGR. E-mail: jp_oliveira19@hotmail.com

2 Estudante do curso de Administração da FMGR. E-mail: thales.cavalcanti.araujo@gmail.com. Aspirante a oficial da reserva do Exército Brasileiro - CPOR-Recife; técnico em design e multimídia para jogos digitais ETE Cícero Dias.

3 Orientador. Doutor em Educação - Universidade Federal de Pernambuco; Administrador - Universidade de Pernambuco - FCAP/UPE; Mestre em Planificación y Gestion Organizacional - Universidad Autonoma de Madrid / Espanha; Mestre em Dirección y Organización de Hospitales y Servicios de Salud - Universidad Politécnica de Valencia / Espanha; Especialista em Marketing - FCAP/UPE; Consultor em Sistemas Organizacionais desde 1984; Professor e Diretor Acadêmico da Faculdade Metropolitana da Grande Recife.

E-mail: arandi.campelo@globo.com
\end{abstract}


communication between sectors contributes to business productivity, in addition to observing the cause of conflicts in the company, suggesting a way of reconciling these conflicts, aiming the general welfare. The survey and analysis were carried out through field research through a semi-open questionnaire applied between 10/21/2019 and 10/24/2019. From 76 people involved in the company's commercial and transportation sector, $19(25 \%)$ participated in the questionnaire. The study revealed that communication is essential for a company to be productive, as it covers all stages of the process and the relationship between people, also creating a favorable environment to work when done correctly. It was also observed that there are always conflicts in the company, but they are not so relevant in most cases and the way to resolve these conflicts is very fast and effective.

Keywords: Communication. Organizational culture. Motivation. Conflicts. Personal influence. Professional quality.

\section{INTRODUÇÃO}

A comunicação é fator essencial na interação entre todos os atores envolvidos em uma instituição, além de ser fator preponderante para o desenvolvimento de qualquer organização. Em uma sociedade globalizada e interligada pela internet, redes sociais e mídias virtuais, a organização que não possuir uma comunicação eficiente e eficaz acabará se prejudicando, podendo haver conflitos e insatisfações nas relações interpessoais.

A instituição que não investir ou negligenciar a importância da comunicação como ferramenta essencial, acabará por prejudicar a alavancagem do desenvolvimento organizacional.

Segundo Haroldo Pereira (2005), a comunicação é o simples fato de um ser A transferir uma informação para um ser B. É a forma de um ser interagir com outros seres, trocando informações de seu interesse. A comunicação é um processo social básico, essencial. Sem comunicação a sociedade não evolui.

\section{REFERENCIAL TEÓRICO}

A comunicação é uma ferramenta bastante utilizada por todos nós desde o momento em que acordamos até o momento de nos recolhermos. Ela está presente em várias situações do nosso cotidiano, principalmente em nosso ambiente de trabalho.

Mesmo com o potencial avanço dos meios de comunicação, os conflitos gerados entre as pessoas ainda continuam bastante presentes em nossas relações. Segundo Mcintyre, (2007), o conflito é o processo que começa quando uma das partes envolvidas nota que a outra a afetou ou a afetará de forma negativa. Além disso, essa definição tem três características: o conflito tem que ser percebido, do contrário não existe conflito; tem que existir uma interação; 
tem que haver uma incompatibilidade entre as partes. Percebemos, assim, que o conflito não é estático, mas uma sequência de acontecimentos.

\section{CONFLITOS NO AMBIENTE ORGANIZACIONAL}

A comunicação entre pessoas é uma atividade de trocas de informações (símbolos, palavras ou sons) que abordam incontáveis temas e assuntos. Aprofundando esta temática no contexto organizacional, é possível dizer que a comunicação entre pessoas, dentro das organizações, é uma ação indispensável e se faz totalmente presente, principalmente quando se trata de colaboradores de um mesmo setor da empresa, ou seja:

A necessidade de se comunicar de modo eficaz sempre esteve no topo da lista de prioridades de todo supervisor, que não só deve fazer o possível para se comunicar bem com seus funcionários como também deve conhecer os fatores que podem prejudicar suas tentativas nesse sentido, e saber como superar tais obstáculos. (AMACOM, 1999, p. 7).

No ambiente de trabalho há pessoas com opiniões diferentes e personalidades distintas. Consequentemente, isso gera conflitos entre os colaboradores da empresa, apesar de trabalharem para alcançarem objetivos comuns, com o intuito de um melhor funcionamento da organização. Na visão de Chiavenato (2004), O conflito numa empresa pode ser classificado de cinco formas distintas:

a) Interpessoal - Ocorre quando os indivíduos divergem uns dos outros nas ideias e opiniões. Todavia é considerado natural esse tipo de conflito que deve ser regulado para ajudar no crescimento pessoal ou desenvolver as relações com outras pessoas;

b) Intragrupal - É um conflito que acontece entre os indivíduos, dentro da mesma equipe. Essa discordância entre os membros pode levar ao desentendimento do grupo;

c) Conflito intergrupal - Ocorre quando equipes diferentes de uma mesma empresa se desentendem. Por exemplo, o departamento de vendas de uma organização pode entrar em conflito com o departamento de suporte ao cliente. Isso se deve aos variados conjuntos de metas e interesses desses diferentes grupos;

d) Intrapessoal - São os conflitos que ocorrem interiormente em cada indivíduo. A experiência ocorre na mente da pessoa, por isso, é um tipo de conflito psicológico envolvendo os pensamentos, valores, princípios e emoções. O conflito intrapessoal pode vir de diferentes maneiras, desde um simples problema do dia a dia, até aqueles que podem afetar grandes decisões, como escolher uma carreira; 
e) Conflito de interesses no serviço público e corporativo - Apesar de ser deixado de lado pela grande maioria das classificações, pois muitas vezes é classificado como um subtipo, o conflito de interesses merece um destaque especial. Ele ocorre quando os objetivos de duas partes, sejam elas grupos ou indivíduos, se tornam incompatíveis.

Analisando esses conceitos sobre conflitos, Berg (2012, p. 18) dá grande ênfase à importância do lidar com esse fenômeno organizacional, ao afirmar que "O conflito nos tempos atuais é inevitável e sempre evidente. Entretanto, compreendê-lo e saber lidar com ele é fundamental para o sucesso pessoal e profissional".

Aqui cabe uma indagação: como superar ou evitar os conflitos? Amacom (1999) já abordava muito bem essa questão quando dava algumas dicas consideradas bastante atuais: deve-se manter a conversa fora do círculo de assuntos pessoais, ou seja, assuntos que há divergência política e de valores, mantendo assuntos apenas de interesse corporativo; ser profissional o tempo todo, evitando atacar outras pessoas com assuntos de âmbito pessoal; é muito importante elogiar um subordinado ou um colega de trabalho, causando assim encorajamento e motivação para fazer um trabalho bem feito e em equipe.

Nessa perspectiva é possível chegar à conclusão de que a comunicação empresarial feita de forma correta, sensata e pensada previamente pode evitar vários conflitos interpessoais desnecessários. Tomando como referência o ex-presidente do Conselho Federal de Profissionais de Relações Públicas, Valentin Lorenzetti (2005): “[...] comunicação empresarial não tem segredo, precisa só de competência".

\section{CLIMA ORGANIZACIONAL}

O conceito de clima organizacional é visto de modo geral como a qualidade ou propriedade do ambiente organizacional, que é percebida ou experimentada pelos membros da organização e influencia no seu comportamento. O clima organizacional pode ser considerado positivo quando satisfaz desejos e necessidades dos colaboradores, influenciando-os e motivando-os a trabalhar mais e melhor, com sentimento de satisfação e até mesmo autorrealização. Em contrapartida, o clima pode ser considerado negativo quando desfavorece parcialmente ou totalmente as necessidades do colaborador, trazendo insatisfação e aversão ao trabalho. Logo, podemos afirmar que o crescimento de qualquer organização depende, necessariamente, do desenvolvimento de seus colaboradores e, se as pessoas quiserem superar padrões e atingir níveis mais elevados de responsabilidade, elas precisarão ser treinadas. As chances de sucesso são maiores quando os trabalhadores estão motivados, porém a motivação 
está relacionada ao valor do profissional perante a organização, o reconhecimento, a atenção, por conseguinte o compromisso de ambos são fatores primordiais (LIMA, 2014).

Chiavenato (2004, p. 53), considera que “o clima organizacional é favorável quando proporciona satisfação das necessidades pessoais dos participantes, produzindo elevação do moral interno. É desfavorável quando proporciona frustração daquelas necessidades”.

A definição do clima organizacional é como o resultado do estado de espírito ou do ânimo das pessoas, que predomina em um ambiente organizacional em um determinado período. (LUZ, 2003).

Nos conceitos dos diferentes autores, sobre clima organizacional, é possível encontrar, pelo menos, três palavras-chave que estão quase sempre presentes. São elas:

Satisfação - Esta é uma das palavras mais presentes nos conceitos dos diferentes autores. Direta ou indiretamente os conceitos nos remetem à relação do clima com o grau de satisfação das pessoas que trabalham em uma organização.

Percepção - Outra importante palavra contida nos conceitos de clima refere-se à percepção que os funcionários têm sobre os diferentes aspectos da empresa que possam influenciá-los, positiva ou negativamente. Portanto, se os funcionários percebem a empresa positivamente, o clima dessa empresa tende a ser bom; ao contrário, se eles percebem mal a empresa, o clima tende a ser ruim.

Cultura (organizacional) - Alguns autores tratam clima e cultura como coisas parecidas, fazendo sempre menção à cultura quando se referem ao clima. Isso porque a cultura influencia, sobremaneira, o clima de uma empresa. São faces de uma mesma moeda. São questões complementares.

A cultura organizacional influencia o comportamento dos indivíduos e dos grupos. Ela impacta diretamente no dia a dia da empresa, nas decisões, nas atribuições dos funcionários, nas formas de acordo, recompensas e punições, relacionamentos, layout e mobiliário, processo de comunicação, modo como os funcionários se vestem e assim por diante (LUZ, 2003).

Schein (2010) diz que a cultura organizacional é um conjunto de pressupostos básicos que um grupo inventou, descobriu ou desenvolveu ao aprender como lidar com os problemas de adaptação externa e integração interna.

\section{PRODUTIVIDADE NA EMPRESA}

Numa visão geral, a produtividade é considerada uma sincronia de estratégias das empresas com o mercado, mostrando o quanto ela pode se sobressair, sendo bastante eficaz na 
produção de serviços e/ou produtos, atendendo às necessidades do próprio mercado. Desta forma, Cerqueira Neto (1991, p. 43) define que "as grandes empresas se empenham na implementação de programas de qualidade total, cujos resultados não só garantem a plena satisfação dos clientes como também reduzem os custos de operação, minimizando as perdas, diminuindo consideravelmente os custos com serviços externos, otimizando a utilização dos recursos existentes".

Atrelado ao foco principal do tema aqui abordado, o pensamento de Longenecker, Moore e Petty (1997) reforçam que produtividade é a eficiência dos insumos transformados em produção. A administração de operações e de produção tem sofrido grandes transformações com as mudanças do mercado. As empresas devem sempre aprimorar a produtividade, qualidade e eficiência, o que exige boa estruturação, comunicação fácil e ambiente de valorização do ser humano.

Para que estejam inclusas neste contexto, algumas empresas adotaram técnicas de qualidade, queima de linhas de produtos não competitivos, adoção de fluxo de produção mais eficiente, reuniões periódicas com os colaboradores, apresentando o feedback dos pontos fortes e pontos a melhorar, avaliação de desempenho, dentre outros processos que torne a empresa mais competitiva.

É de grande importância que as empresas se esforcem em ações focadas na sua melhoria contínua, pois do contrário perderão espaço no mercado para as que se mantêm na onda da atualização constante e progressiva. Esse esforço, embora exija investimentos, muitas vezes acima da disponibilidade das organizações, é indispensável num mercado cada vez mais competitivo. Como bem afirmou Corrêa (2009, p. 222), "é impossível para uma empresa permanecer competitiva se se mantiver fazendo as coisas da mesma forma por longos períodos: ela será logo superada por concorrentes em evolução constante. A única saída é melhorar".

Diante desta afirmação é possível fazer uma síntese, mostrando que é de vital importância que as organizações se esforcem em ações focadas na sua melhoria contínua, pois, do contrário, poderão perder espaço no mercado para as que se mantêm sempre atualizadas.

Outro aspecto importante que evidentemente envolve a produtividade atrelada à comunicação é o planejamento, que pode ser definido como uma reunião de informações organizadas e compartilhadas entre colaboradores, visando à tomada de decisão para acarretar numa futura consequência positiva para a empresa. "Em suma, a eficácia futura de um ciclo estará baseada num bom planejamento, o qual proverá dados e informações às etapas restantes.” (BADIRU, 1993, p. 353). 


\section{METODOLOGIA}

O objeto de estudo deste artigo consiste na comunicação empresarial. Com esse foco, a pesquisa pretende identificar a influência da comunicação na produtividade da empresa e analisar a resolução dos conflitos interpessoais na organização, decorrentes dos diversos fatores que influenciam uma boa comunicação.

A pesquisa teve como campo investigativo a empresa KarneKeijo Logística Integrada 4 , localizada na BR 101 Sul, Barro, Recife-PE.

Para levantamento dos dados de campo foi considerado um total de 76 colaboradores que estão lotados no setor comercial e de transporte da empresa, tomando-se como amostra $25 \%$ desse total, o que corresponde a 19 pessoas que colaboraram com este trabalho.

A pesquisa, que foi bibliográfica e de campo, com método de análise propositivo, na forma qualitativa, teve como principal instrumento de coleta um questionário semiaberto.

\section{DESENVOLVIMENTO DA PESQUISA DE CAMPO}

A pesquisa de campo foi realizada no período de 21 a 24 de outubro de 2019 e teve uma boa aceitação e receptividade das pessoas que fizeram parte da amostra. Não houve grandes dúvidas com relação às perguntas do questionário. No contexto da pesquisa de campo foram considerados os seguintes temas:

a) Natureza dos conflitos interpessoais existentes na KarneKeijo;

b) Como a comunicação interfere no clima organizacional da empresa;

c) Qual a relação existente entre comunicação e produtividade na instituição.

\section{RESULTADOS DA PESQUISA DE CAMPO}

No que tange à existência de conflitos, foi perguntado se eles existem e se são relevantes entre os colaboradores da empresa. 63\% dos participantes disseram que não existem conflitos relevantes na KarneKeijo. Já os 37\% restantes afirmaram que existem conflitos relevantes entre os colaboradores da empresa e, na maioria das vezes, se apresentam como conflitos interpessoais. As razões deste número podem ser entendidas como uma comunicação clara, estrutural, aberta e que faz da empresa KarneKeijo uma organização boa de se trabalhar, tendo como ponto positivo uma boa interação entre seus funcionários e a minimização dos conflitos.

4 KarneKeijo é uma empresa fundada em 27 de novembro de 1978 com a razão social Giselda Maria de Aguiar Barreto-ME. Na atual direção de Inácio Miranda, a empresa tem as segmentações de Food Service (lanchonetes, restaurantes, pizzarias e etc.) e de Varejo (supermerc ados e mercadinhos). 
Quanto à questão relativa à comunicação, 42\% concordaram plenamente e 37\% concordaram parcialmente quando foram perguntados se na KarneKeijo a comunicação funciona de forma eficiente e se mostra de grande valia para o crescimento e desenvolvimento da organização. Fazendo uma síntese das respostas, a maioria concorda que a comunicação é fundamental para o desenvolvimento e crescimento da empresa, assim como a melhor relação dentro dela, porém afirmam que não é sempre de maneira eficiente que a comu nicação ocorre na empresa. Somente $21 \%$ dos entrevistados têm opiniões que divergem totalmente quando se diz respeito ao que foi proposto, havendo então situações diferentes do que foi dito pelos autores no referencial teórico e o que na prática acontece.

Ao serem indagados sobre a questão da relação entre comunicação e produtividade, $95 \%$ dos entrevistados confirmaram o que havia sido mencionado pelos autores no referencial teórico, dizendo que a comunicação tem sim ligação direta com a produtividade na empresa.

Por fim, ao serem abordados sobre planejamento estratégico, produtividade e comunicação $79 \%$ deram a opinião de que a comunicação é satisfatória, necessitando de melhorias, mas é eficaz ao atingir metas. 16\% disseram que a comunicação é clara e concisa, funcionando de maneira impecável. Apenas 5\% opinaram que a comunicação é ruim, havendo falhas de comunicação entre as lideranças e os setores envolvidos.

\section{CONSIDERAÇÕES FINAIS}

Diante do apresentado neste artigo foi possível identificar algumas falhas e insatisfações no método de comunicação entre os colaboradores. Embora todos concordem que a comunicação entre setores contribui para a produtividade da empresa, foi observada a causa de conflitos e sugerida uma forma de conciliação a fim de restabelecer o bem comum a todos.

Podemos concluir que a comunicação é fundamental para o desenvolvimento da empresa, assim como para o seu clima organizacional. Compartilhar um clima mais leve e mais tranquilo entre os colaboradores ajuda a melhorar os resultados da empresa. Conflitos sempre vão existir, assim como divergência de informações e de opiniões. Cabe ao líder ou às próprias pessoas envolvidas procurar sempre a conciliação, visando um objetivo comum, geralmente alinhando os interesses dos funcionários com os interesses da empresa. Essas práticas são as mesmas recomendadas pelos autores vistos no referencial teórico.

Diante do estudo e da pesquisa de campo realizada, sugere-se que a comunicação na organização seja feita de forma clara e objetiva, evitando assuntos pessoais e irrelevantes que possam causar polêmica ou divergência de opiniões, colaborando para que o clima organizacional permaneça bom e ideal para se trabalhar. Recomenda-se também, com relação 
aos conflitos, que sejam resolvidos de forma rápida e objetiva, sendo alinhados os interesses dos colaboradores com os interesses da empresa. Isso tudo, quando realizado de maneira correta, contribui positivamente para a produtividade na organização.

\section{REFERÊNCIAS}

AMACOM. American Management Association. Como se comunicar com eficácia. Rio de Janeiro: Campus, 1999.

BADIRU, A. B.; AYENI, B. J. Practitioner's guide to quality and process improvement. London: Champman \& Hall, 1993.

BERG, Ernesto Artur. Administração de conflitos: abordagens práticas para o dia a dia. Curitiba: Juruá, 2012.

CAHEN, Roger. Comunicação Empresarial: a imagem como patrimônio da empresa e ferramenta de marketing. 10. ed. Rio de Janeiro: Best Seller, 2005.

CHIAVENATO, Idalberto. Gestão de pessoas: o novo papel dos recursos humanos nas organizações. 13. ed. Rio de Janeiro: Campus, 2004.

CORRÊA, Carlos A., CORRÊA, Henrique L. Administração de Produção e Operações. Manufatura e Serviços: uma abordagem estratégica. 2. ed. São Paulo: Atlas, 2009.

LIMA, R. A. A atuação do Estado brasileiro e a crise empresarial na perspectiva da lei de falências e de recuperação de empresas. Rio de Janeiro: Lumem Juris, 2014.

LONGENECKER, Dwight, MOORE, C. J., PETTY, J. W. Administração de pequenas empresas. 13. ed. São Paulo: Cengage Learning, 1997.

LUZ, Ricardo. Gestão do Clima Organizacional. Rio de Janeiro: Qualitymark, 2003.

NETO, Cerqueira. Gestão da qualidade: princípios e métodos. São Paulo: Pioneira, 1991.

MCINTYRE, S. E. Como as pessoas gerem o conflito nas organizações: estratégias individuais negociais. Análise Psicológica, São Paulo, v. 25, n. 2, p. 295 -305, abr. 2007.

PEREIRA, H. Curso Básico de Teoria da Comunicação, São Paulo: Quartet, 2005.

SCHEIN, Edgar H. Cultura organizacional e liderança. 3. ed. São Paulo: Atlas, 2010. 


\section{Apêndice A - Modelo de questionário para a pesquisa de campo}

Este questionário tem como objetivo coletar dados sobre a comunicação empresarial e seus conflitos interpessoais atrelados à produtividade da empresa Karnekeijo.

1-Você considera a KarneKeijo um bom lugar para trabalhar?

( ) $\operatorname{Sim}$

( )Não

2- Os colaboradores realizam suas atividades de forma integrada e se ajudam mutuamente?

( ) A maioria da equipe se ajuda

( ) Cada um prefere fazer o seu

( ) Não sei dizer

3- Para você qual a melhor maneira de resolver um conflito?

( ) Os colegas devem resolver entre si

( ) O líder da equipe deve intermediar

( ) Outra:

4- Existem conflitos relevantes entre os colaboradores da sua empresa?

( ) ( ) Sim

Se positivo, de que natureza?

a) ( ) Entre pessoas

b) ( ) Entre grupos de pessoas, de setores distintos

c) ( ) Entre grupos de pessoas, de mesmos setores

d) ( ) Conflito de interesses distintos e incompatíveis

e) ( ) Conflitos dentro do próprio indivíduo

5- A KarneKeijo lhe permite usar seus conhecimentos e habilidades para fazer algo diferente na sua rotina de trabalho?

( ) $\operatorname{Sim}$

( )Não

6-Você se sente reconhecido e valorizado pelo seu trabalho?
( ) Sinto-me reconhecido e valorizado
( ) Não me sinto reconhecido
( ) Sinto-me pouco valorizado

Por quê?

7-Você indicaria a KarneKeijo como uma empregadora de um familiar ou amigo(a)?

( ) $\mathrm{Sim}$

( )Não

8- Você acha que a comunicação tem ligação direta com a produtividade na empresa?

( ) $\operatorname{Sim}$

( )Não

9- Na KarneKeijo a comunicação funciona de forma eficiente e se mostra de grande valia para o crescimento e desenvolvimento da organização?

( ) Sim, concordo plenamente

( )Concordo parcialmente. Não é tão eficiente

( )Discordo. Não há qualquer relação entre comunicação eficiente e produtividade

10- Você considera que as estratégias de produtividade da KarneKeijo a faz ser competitiva no mercado?

( ) Sim

( )Não 
11 - Quando se trata de planejamento estratégico, visando maior produtividade, como você avalia a comunicação na empresa?

( ) A comunicação é clara e concisa, funcionando de maneira impecável

( ) A comunicação é satisfatória, necessitan do de melhorias, mas é eficaz ao atingir metas.

( ) Ruim. Há sempre falhas de comunicação entre as lideranças e os setores envolvidos.

\section{Apêndice B - Gráficos das questões abordadas no questionário}

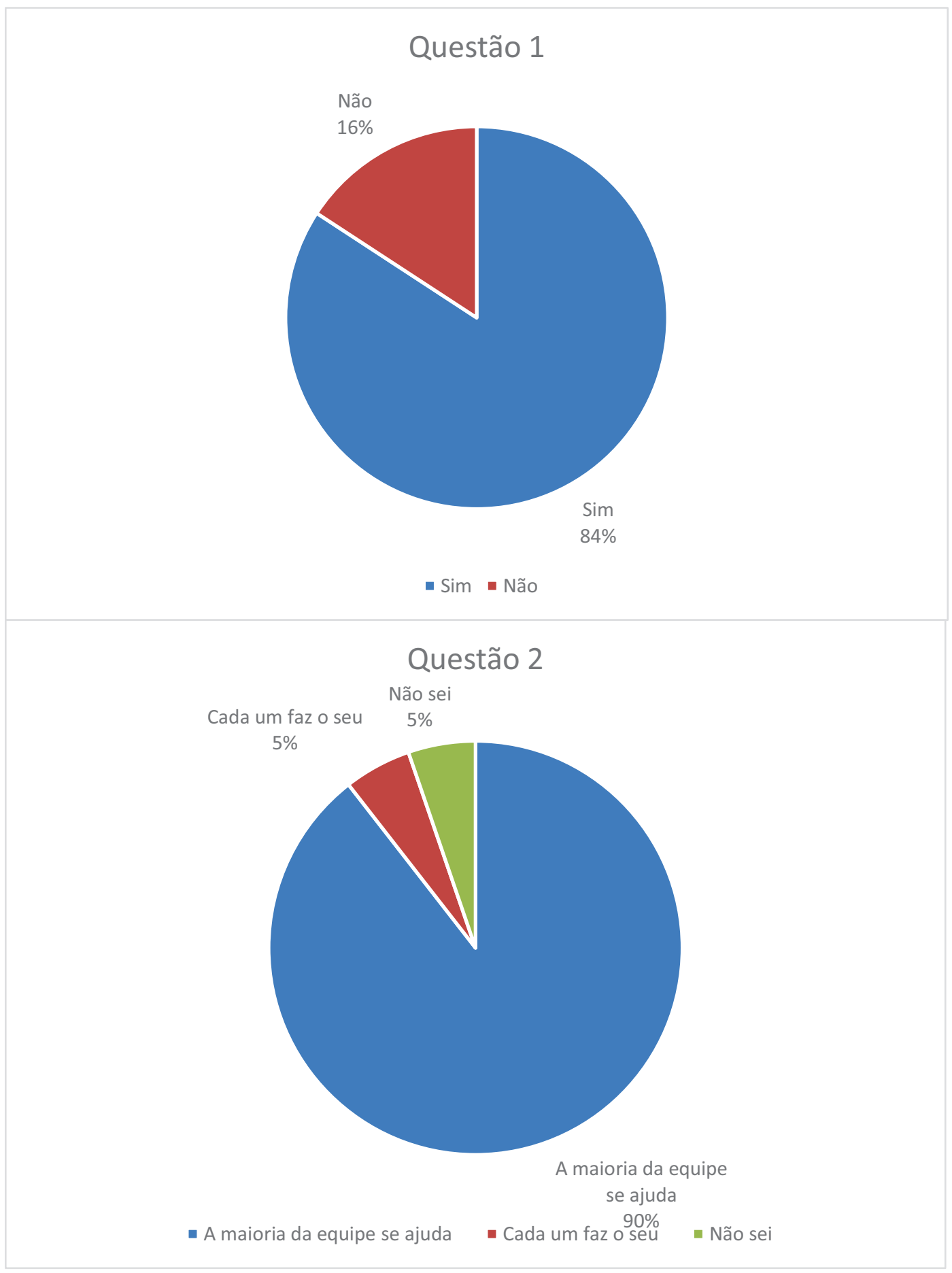




\section{Questão 3}

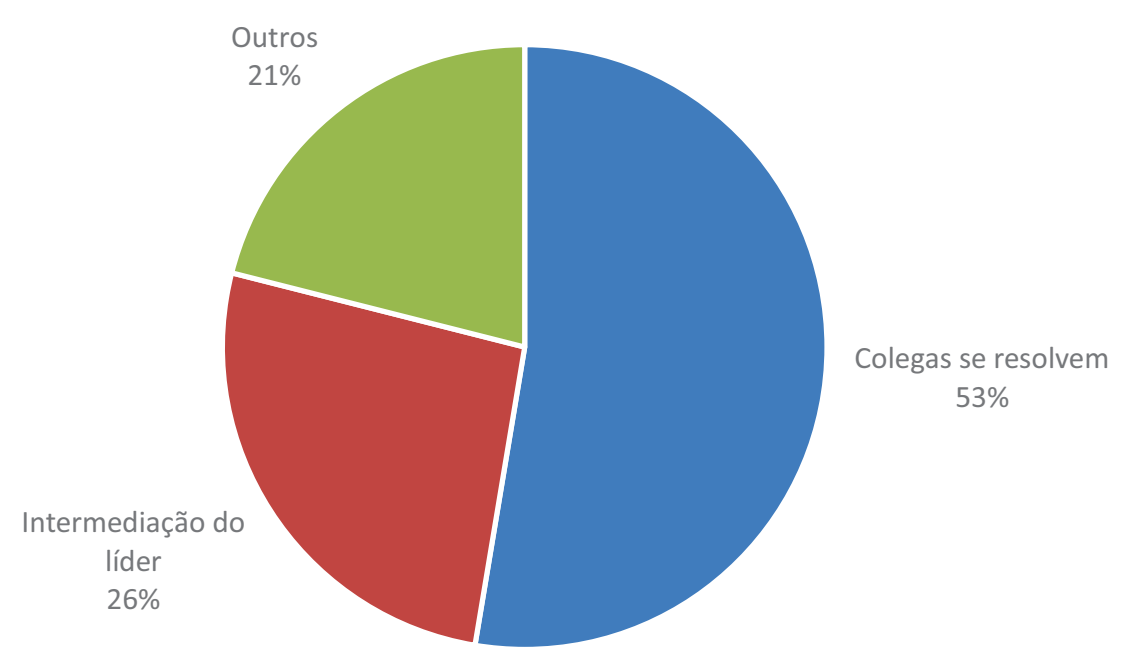

- Colegas se resolvem - Intermediação do líder - Outros

\section{Questão 4}

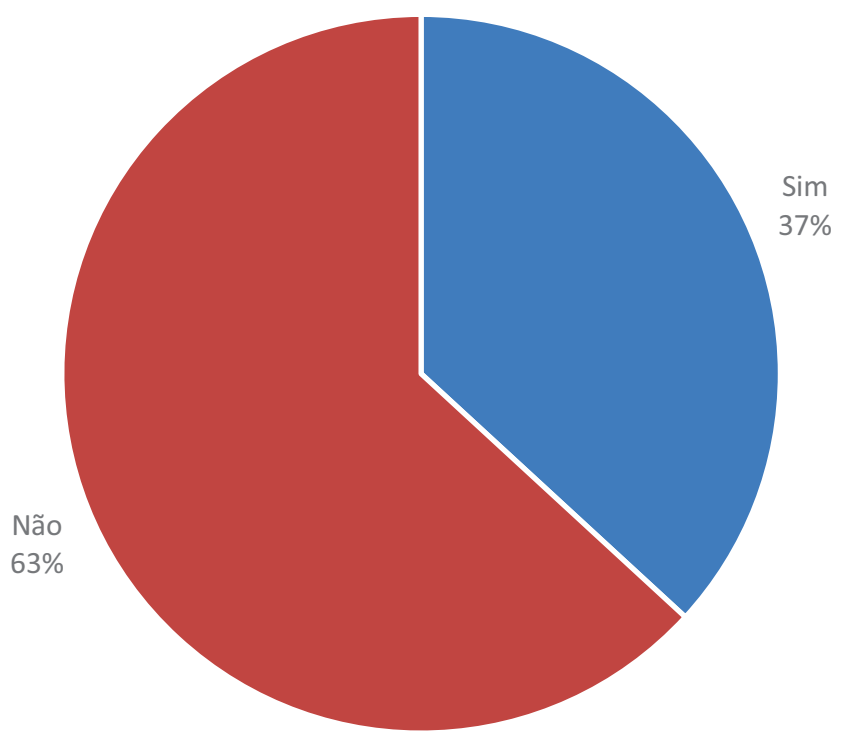

- Sim - Não 


\section{Questão 5}

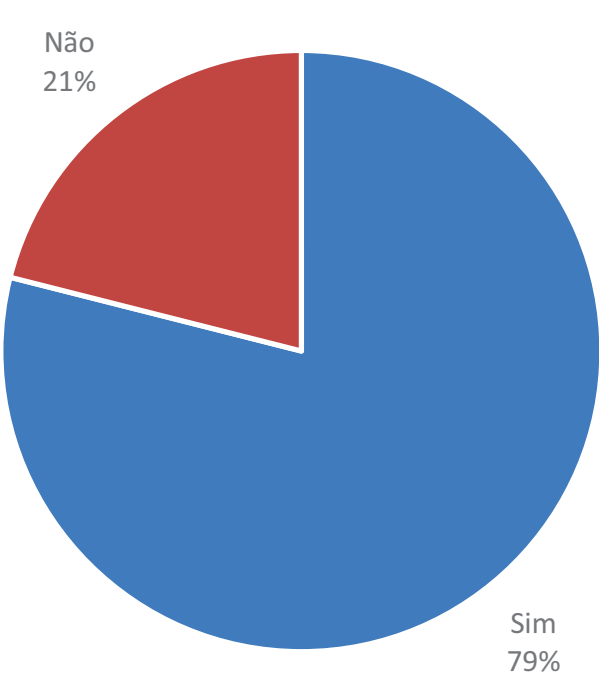

- Sim - Não

\section{Questão 6}

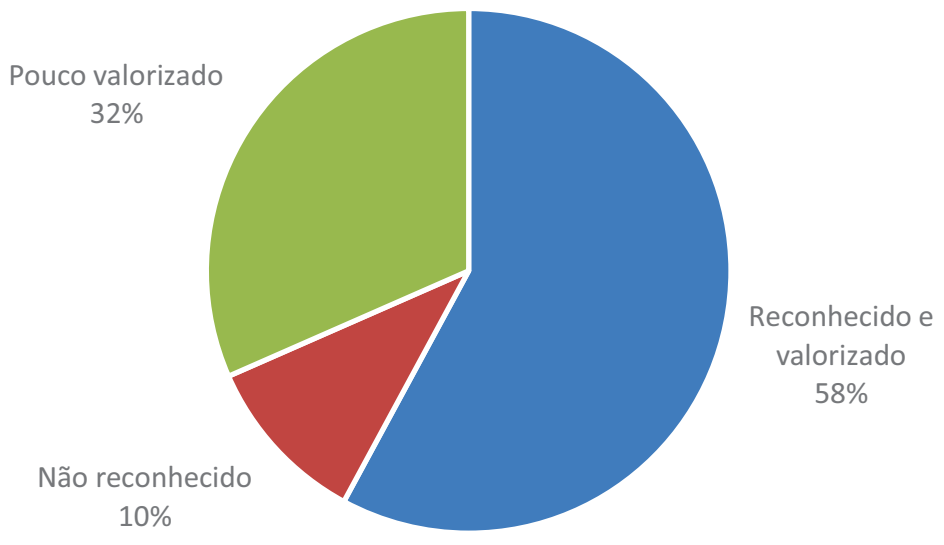

- Reconhecido e valorizado - Não reconhecido - Pouco valorizado 

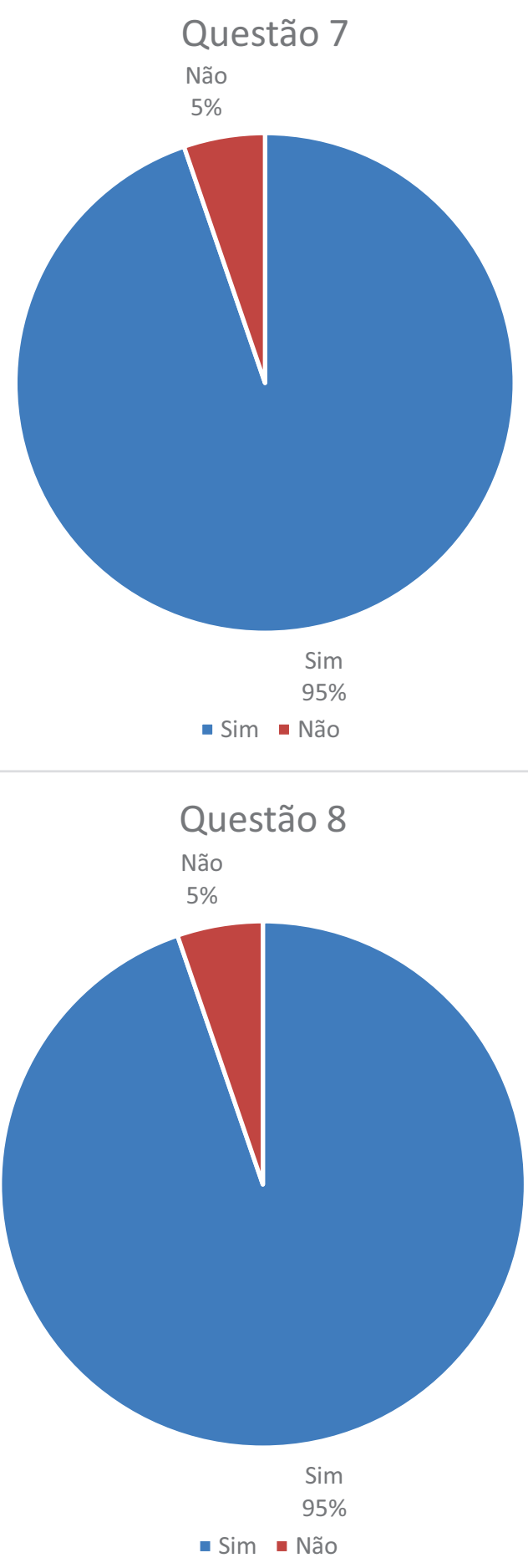


\section{Questão 9}

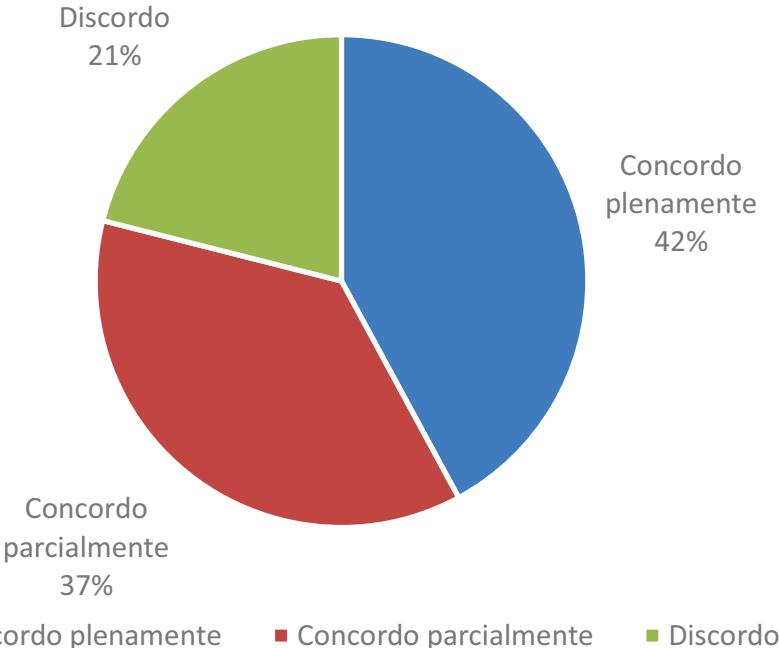

- Concordo plenamente - Concordo parcialmente Discordo

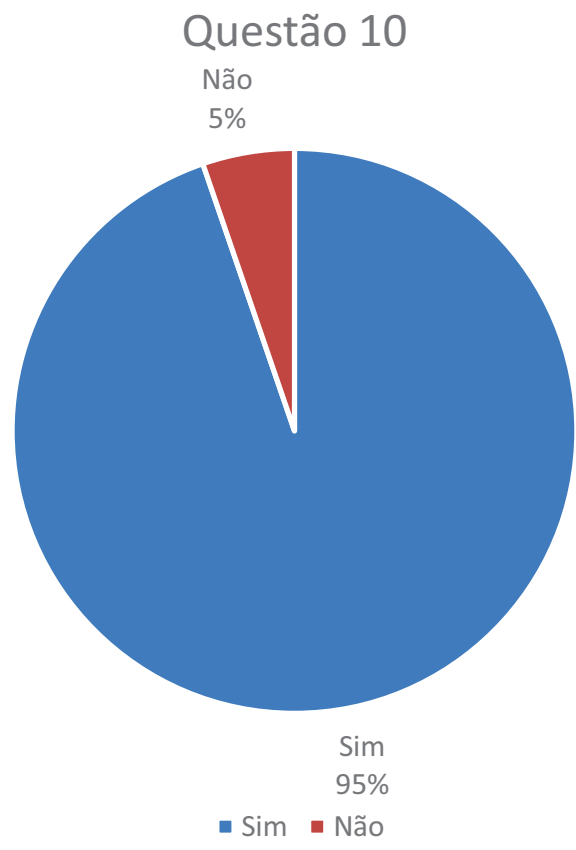




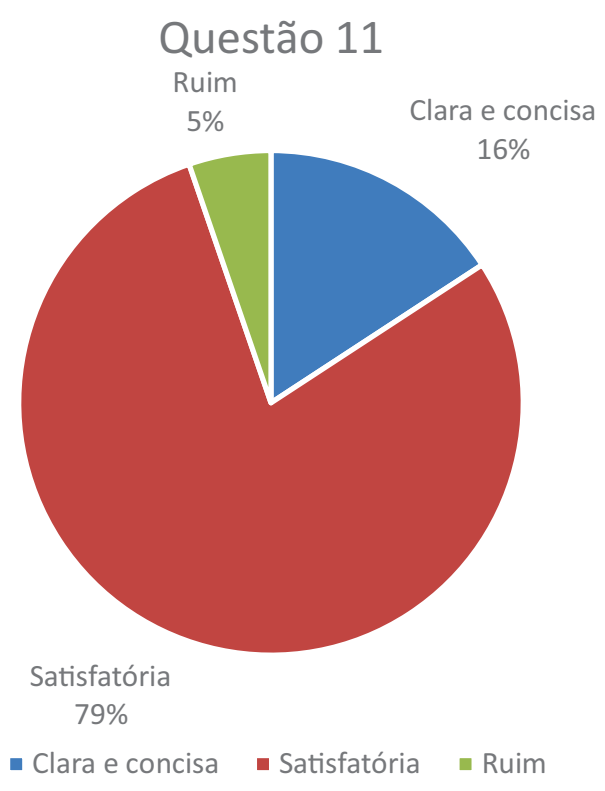

